\title{
Matrix Metalloproteinase-2, COL1A1, and COL3A1 mRNA Expression in Aponeurosis Musculus obliquus Externus Abdominis of Adult Inguinal Hernias
}

\author{
Nizar Nizar ${ }^{1 *}$, Afriwardi Afriwardi ${ }^{1}$, Yanwirasti Yanwirasti ${ }^{1}$, Alsen Arlan $^{2}$ \\ ${ }^{1}$ Department of Biomedical Science, Faculty of Medicine, Universitas Andalas, Padang, Indonesia; ${ }^{2}$ Departement of Surgery, \\ Faculty of Medicine, Universitas Sriwijaya, Palembang, Indonesia
}

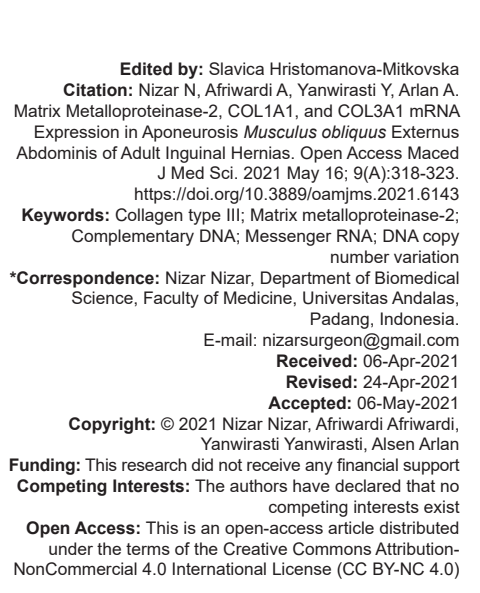

Abstract

BACKGROUND: The ratio change of type I and type III collagen in the peritoneal tissue can be associated with defects in collagen synthesis caused by the extracellular matrix's degradation. Matrix metalloproteinase-2 (MMP-2) is an enzyme that contributes primarily to the degradation of this extra cell.

AIM: This study aimed to analyze the differences in expression of COL1A1, COL3A1, and MMP-2 mRNA and the relationship between these expressions in adult inguinal hernias and the expression ratio between the COL $1 A 1 /$ COL3A1 genes.

METHODS: This study was an observational study with a cross-sectional comparative study design, where the sample was adult inguinal hernia patients who were taken from the aponeurosis tissue $\mathrm{m}$. external obliquus performed at the time of surgery, while control was a non-herniated patient. The sample RNA was isolated, followed by cDNA synthesis, and examined by real-time polymerase chain reaction.

RESULTS: The mean values of expression for COL1A1, COL3A1, and MMP-2 in the case group were $40.02 \pm$ 181.38 copy number, $33.70 \pm 143.62$ copy number, and $31.78 \pm 84.47$ copy number. Meanwhile, the expression values for COL1A1, COL3A1, and MMP-2 in the control group were $40.247 \pm 162.837$ copy number, $13.35 \pm 37.43$ copy number, and $20.58 \pm 48.95$ copy number.

CONCLUSIONS: Our study showed a difference in COL3A1 expression between the hernia and non-hernia groups, and no difference was found in the expression of COL1A1 and MMP2 between the hernia and non-hernia groups.

\section{Introduction}

Inguinal hernia is a problem in surgical health because the incidence of this case is mostly after appendicitis. From all cases of abdominal hernias, 27\% are inguinal hernias [1], [2]. In the United States, hernia incidence was ranked in the top five in 2007; around 700,000 hernia operations are performed annually and cost about three billion dollars a year [3], [4].

The etiology and pathogenesis of adult inguinal hernias are very complex, with various factors contributing to their development. The procedure that has been implemented often causes recurrence and contralateral hernias, resulting in high costs for second treatment and surgery, even slow recovery [2]. There is an increase in morbidity, and it is not clear what causes it can reduce the incidence of inguinal hernias. A trigger factor caused the manifestation of a hernia. Hernia inguinal caused an increase in intra-abdominal pressure due to congenital diseases, but this opinion also had not had strong evidence.

In adult primary hernias, it is found that the internal annulus is a defect or a weak place in the emergence of a lateral inguinal hernia which causes the entry of the abdominal contents into the inguinal canal. The structure of the canal is formed by the external obliques and transverse fascia muscles. In inguinal hernias, transverse fascia and external obliquus muscles are the main anatomical structures with two structural components: collagen and elastin [5], [6].

Collagen is the extracellular matrix's main substance and is the main protein against resistance forces in a stressful process [6]. Impaired collagen metabolism leads to decreased tensile strength and stability mechanisms of connective tissue and induces scarring. Collagen synthesis and abnormal metabolism are thought to play an essential role in the development of inguinal hernias. Researchers' attention is currently focused on procollagen types I and III in looking for the pathogenesis of the inguinal hernias [7]. The ratio changes of these types in the abdominal hernia wall tissue can be associated with defects in collagen synthesis or abnormal collagen expression due to the degradation of the extracellular matrix. The enzymes which contribute more to extracellular degradation are matrix metalloproteinases (MMPs). It is currently 
suspected that MMP-2 is a proteolytic enzyme in the pathophysiology of inguinal hernia. Overexpression is especially increased in inguinal hernias [8].

\section{Methods}

\section{Research design}

This study was an observational study with a cross-sectional comparative study design, where the sample was adult inguinal hernia patients taken from the aponeurosis tissue $\mathrm{m}$. external obliquus performed at the time of surgery, while control was a non-herniated patient. The patients in the case group were 18 years old, suffered from an inguinal hernia, and had surgery in three general hospitals in Jambi, Indonesia. The control group consisted of patients who underwent abdominal surgery (appendectomy, vesicolithotomy, or exploratory laparotomy) and did not have an inguinal hernia. The patient should meet the inclusion criteria (patients over or equal to 18 years of age and willing to be the subject of research). The exclusion criteria were patients who have connective tissue disease. All patients and their families who participated in this study had provided prior informed consent.

\section{Tissue incision technique}

All samples to be taken are muscle tissue aponeurosis Musculus obliquus externus in the abdomen, under general anesthesia. The sampling method was the same for both groups. Sampling was carried out in the operating room. After asepsis and antisepsis procedures were performed in the surgical area, muscle tissue samples were taken through an elliptical incision with a size of $1-2 \times 1 / 2 \mathrm{~cm}$ in the operating room. Sampling is inserted into a tube containing $1 \mathrm{~mL}$ of RNAlater solution (Sigma Aldrich, Singapore) and remains upright so that it is immersed in liquid. Then, put the tube into a special box so that RNAlater remains in an upright position. The samples were stored in the freezer at temperature $-80^{\circ} \mathrm{C}$.

\section{RNA isolation}

The laboratory assessment is carried out at Biomedical Laboratory, Faculty of Medicine, Universitas Andalas. Tissue samples were inserted into the microtube and immersed with RNA later solution. Five hundred microliters of trizol were added into the microtube and then homogenized it using a homogenizer. Incubate the samples for $5 \mathrm{~min}$ at room temperature. Add $100 \mu \mathrm{l}$ of chloroform, then incubate at room temperature for 2-3 $\mathrm{min}$. Then, centrifuge the sample at $\times 12,000 \mathrm{~g}$, temperature $4^{\circ} \mathrm{C}$ for $10 \mathrm{~min}$.
For RNA precipitation, add $250 \mu$ isopropanol $100 \%$. Followed by washing RNA using $500 \mu$ l of ethanol $75 \%$. Vortex the sample for a few seconds, then centrifuge at a speed of $\times 7500 \mathrm{~g}$, temperature $4^{\circ} \mathrm{C}$ for $5 \mathrm{~min}$. RNA resuspension with Rnase-free water (20-50 $\mu$ l) by up and down pipetting. Incubate in a water bath or heat block at $55-60^{\circ} \mathrm{C}$ for $10-15 \mathrm{~min}$. Next, measure the RNA concentration using Nanodrop.

\section{cDNA synthesis}

A mixture of RNA samples, $\times 5$ TransAmp buffer, reverse transcriptase, and nuclease-free water in a polymerase chain reaction (PCR) tube at $4^{\circ} \mathrm{C}$. After everything is mixed, make sure there are no air bubbles in the PCR tube and that no material sticks to the walls of the PCR tube by quick spin down using a centrifuge. Then, insert the PCR tube containing the sample into the thermocycler wells/PCR machine. Set the temperature and duration conditions on the thermocycler/PCR machine as follows $10 \mathrm{~min}$ at $25^{\circ} \mathrm{C}$ (primary annealing), $15 \mathrm{~min}$ at $42^{\circ} \mathrm{C}$ (reverse transcription), and $5 \mathrm{~min}$ at $85^{\circ} \mathrm{C}$ (inactivation). The results of cDNA synthesis can be used directly for real-time PCR.

\section{MMP-2, COL1A1, and COL3A1 measurement}

Mixture real-time PCR reaction components (SsoFast $^{\mathrm{TM}}$ EvaGreen ${ }^{\circledR}$ Supermix, Collagen Primers type 1/type III/MMP-2 - Forward $(10 \mu \mathrm{M})$, Collagen Primers type 1/type III/MMP-2 - Reverse (10 $\mu \mathrm{M})$, Nuclease -free water and cDNA samples) in a PCR tube. The MMP2 sequence with a forward primer consisting of 23 bases, namely 5-TACAGGATCATTGGCTACACACC -3 (Tm: $60.10 \mathrm{C}$ ) and a reverse primer consisting of 21 bases, namely 5-TATCCATCGCCATGCTCCCAG -3 (Tm: $62.10 \mathrm{C}$ ). MMP2 primer attached to the reference gene showed an amplicon length of 170 base pairs. The COL1A1 sequence with a forward primer consisting of 20 bases, namely 5-GACGAAGACATCCCACCAAT-3 (Tm: $57.60^{\circ} \mathrm{C}$ ) and a reverse primer consisting of 18 bases, namely 5-TCGGTGGGTGACTCTGAG-3 (Tm: $\left.57.90^{\circ} \mathrm{C}\right)$. The attachment of the COL1A1 primer to the reference gene showed an amplicon length of 218 base pairs. The COL3A1 sequence with a forward primer was consisted of 18 bases, namely 5-TCCAACTGCTCCTACTCG-3 (Tm: $55.60^{\circ} \mathrm{C}$ ) and with a reverse primary consisting of 18 bases, namely 5-CGAGTCCTCCTACTGCTA-3 (Tm: $54.30^{\circ} \mathrm{C}$ ). Primary attachment of COL3A1 to the reference gene showed an amplicon length of 236 base pairs. Centrifuge by quick spin down using a minicentrifuge, insert the PCR tube into the real-time PCR machine wells. Set the real-time PCR profile on the CFX96 Bio-Rad Instrument, then set the plate according to the test sample position and the sample for the standard curve on the real-time PCR machine wells. The data will automatically come out for analysis. 


\section{Research design}

This study was an observational study with a cross-sectional comparative study design, where the sample was adult inguinal hernia patients taken from the aponeurosis tissue $\mathrm{m}$. external obliquus performed at the time of surgery, while control was a non-herniated patient. The sample RNA was isolated, followed by cDNA synthesis, and examined by real-time PCR.

\section{Ethical approval}

The study was approved by Medical Research Ethical Committee of Faculty of Medicine, Universitas Andalas approval no. 198/EC/UA/2020.

\section{Data analysis}

An independent t-test was used to compare mRNAexpression levels (COL1A1, COL3A1, and MMP-2) between hernias patients and controls (non-hernias). Before the t-test is carried out, the normality test is carried out first using the Shapiro-Wilk test. If data distribution is normal, independent t-test would be used. If it is not normal, data transformation will be carried out. If it is not normal, used a non-parametric test (Mann-Whitney). To analyze the relationship between the variables under study, the Chi-square test was performed.

\section{Results}

\section{Demographic characteristics}

In this study, the mean age of patients in the hernia group was $50.92 \pm 13.09$ years with a range of 25-76 years, while the mean age of non-hernia patients was $36.16 \pm 12.53$ with a range of 20-65 years. Statistically, hernia patients had an older age than non-herniated patients $(p=0.000)$. Furthermore, there were differences in occupation between hernia and non-hernia patients $(p=0.001)$. The majority of hernia patients work as farmers. However, there were no differences in religion, education, occupation, smoking, and disease history between hernia and non-hernia patients $(p>0.05)$

\section{Gene expression}

\section{MMP-2}

The MMP-2 expression value in the case group was $31.78 \pm 84.47$ copy number, even in the control group, the MMP-2 expression value was $20.58 \pm 48.95$ copy number. The MMP2 expression value in hernia patients was higher than in non-hernia patients, but it was not statistically significant $(p=0.621)$ (Table 1$)$.
Table 1: Comparison of MMP-2, COL1A1, and COL3A1 expression between hernia and non-hernia patients

\begin{tabular}{llll}
\hline Variable & Hernia group & Non-hernia group & p-value \\
\hline MMP-2 expression & & & \\
- Mean \pm SD & $31.78 \pm 84.47$ & $20.58 \pm 48.95$ & 0.621 \\
$\begin{array}{l}\text { C Median (Min-Max) } \\
\text { COL1A1 expression }\end{array}$ & $4.27(0.29-411.57)$ & $5.88(0.32-241.35)$ & \\
$\begin{array}{l}\text { - Mean } \pm \text { SD } \\
\text { - Median (Min-Max) }\end{array}$ & $40.02 \pm 181.38$ & $40.25 \pm 162.84$ & 0.295 \\
COL3A1 expression & & & \\
- Mean \pm SD & $33.70 \pm 143.62$ & $13.35 \pm 37.43$ & 0.025 \\
- Median (Min-Max) & $1.61(0.42-721.57)$ & $0.29(0.02-181.65)$ & \\
\hline Mann-Whitney test, $p<0.05$. & & &
\end{tabular}

\section{COL1A1}

The COL1A1 expression value in the case group was $40.02 \pm 181.38$ copy number, while the COL1A1 expression value in the control group was $40.247 \pm$ 162.84 copy number. The COL1A1 expression value in hernia patients was lower than in non-hernia patients, but it was not statistically significant $(p=0.295)$ (Table 1$)$.

\section{COL3A1}

The COL1A1 expression value in the case group was $33.70 \pm 143.62$ copy number, while the COL1A1 expression value in the control group was $13.35 \pm 37.43$ copy number. The COL3A1 expression value in hernia patients was significantly higher than in non-hernia patients $(p=0.025)$ (Table 1$)$.

\section{Relationship between MMP-2 mRNA expression and COL1A1 with COL3A1 gene expression}

\section{Hernia patient}

Based on the Spearman-Rho test, there was a very strong significant positive relationship between MMP2 gene expression and COL1A1 gene expression and a significant weak positive relationship between MMP2 gene expression and COL3A1 gene expression in hernia patients.

\section{Non-hernia patient}

In non-hernia patients, the results showed a moderately significant positive relationship between MMP2 gene expression and COL1A1 gene expression. Furthermore, there was a very weak and insignificant positive relationship between MMP2 COL3A1 gene expression (Figures 1 and 2).

\section{Discussion}

In this study, hernia patients' average age was $50.92 \pm 13.09$ years with a range of 25-76 years, and 

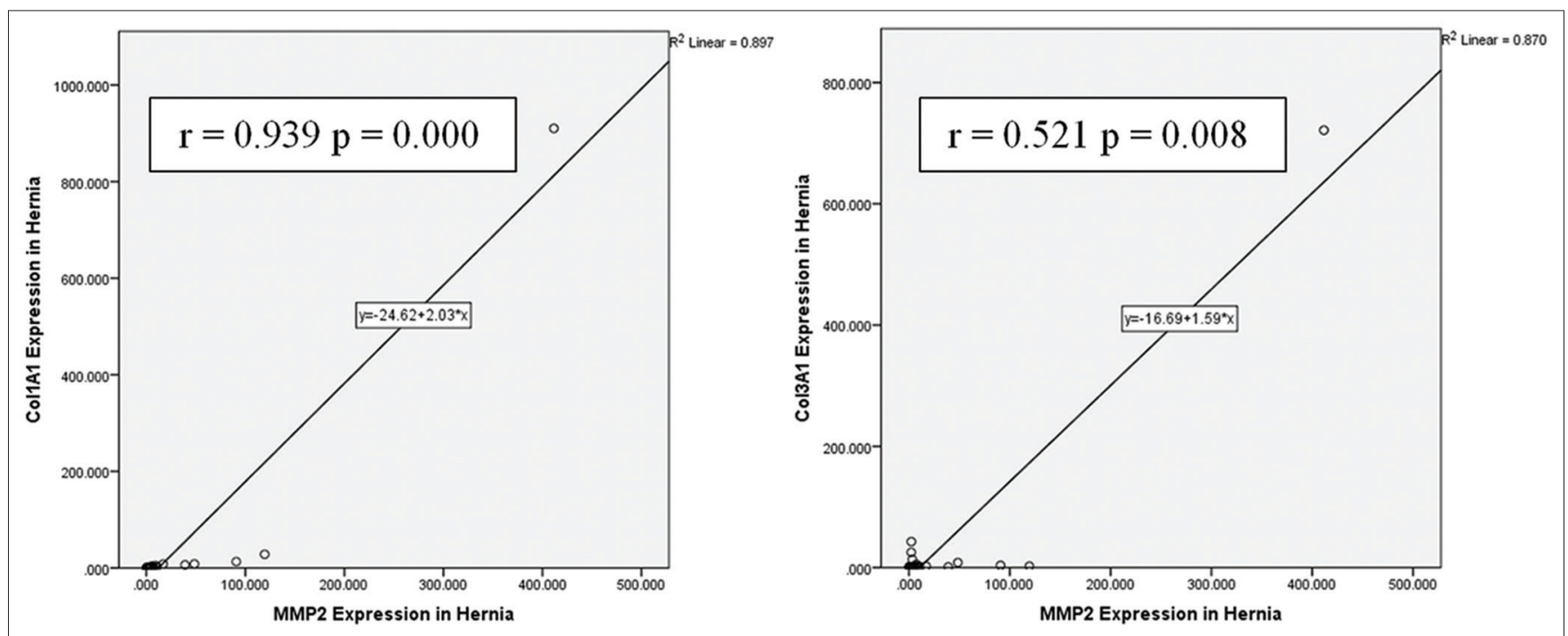

Figure 1: Relationship between matrix metalloproteinase-2 gene expression and COL1A1 with COL3A1 gene expression in hernia patients

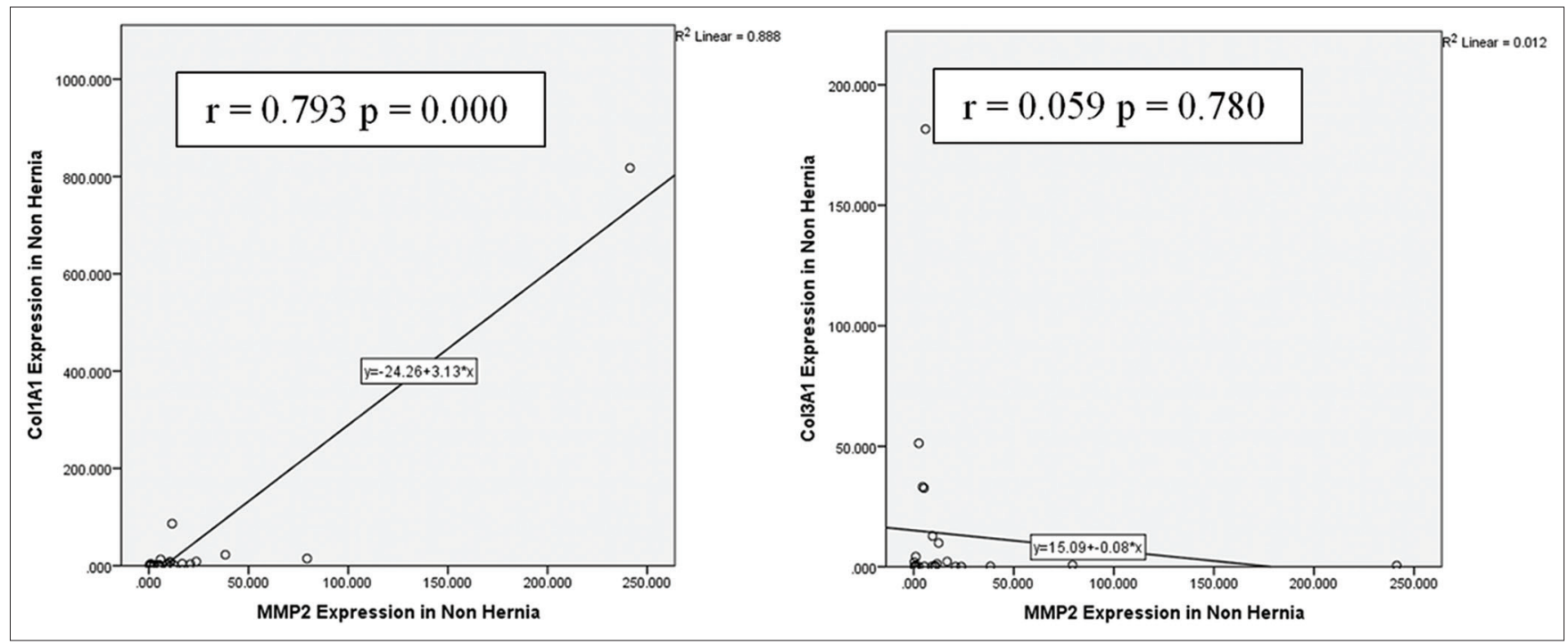

Figure 2: Relationship between matrix metalloproteinase-2 gene expression and COL1A1 with COL3A1 gene expression in non-hernia patients

the majority of patients were 41-60 years old. This result is in line with Quintas et al. [9], which reported that most hernia patients were aged $40-59$ years. Not much different from the research conducted by Claus et al. in 2017, which reported the mean age of bilateral inguinal hernia patients was $51.1 \pm 15.7$ years [10].

Increased age is a significant risk factor for inguinal hernias. Age-induced degradation of the elastic fibers of the inguinal ring is considered to be a contributing factor. The elastic fiber system's quantitative change is in line with the ageing process. There is a significant and progressive reduction of the oxytal fiber (responsible for tissue resistance) and an increase in which is significant in elastic fibers mature elaunin (responsible for tissue elasticity). Besides, there are structural changes in the thickness and wrinkling of the mature elastic fibers. These changes lead to loss of elastic fiber function and loss of interfoveolar ligament adherence. These factors predispose individuals to the development of indirect inguinal hernias that often appear in adults and elderly individuals, especially over the fifth decade [9].

The majority of inguinal hernia patients in this study were farmers. This might be because farmers have had a heavy physical activity associated with the development of inguinal hernias. Abdominal herniation has been associated with a difference between intraabdominal pressure and abdominal wall resistance. Frequent strenuous physical activity invariably increases intra-abdominal pressure, forcing open the processus vaginalis that is not entirely removed in an adult male [11]. The majority of hernia patients are welleducated. In the current era, people are more aware of health, and adequate health facilities make it easier and faster for people to have a checkup if there are symptoms of a disease.

The main types of collagen found in connective tissue are fibrils types I, II, III, V, and XI, with type I collagen being the most abundant protein in humans [11]. 
Collagen type I forms more than $90 \%$ of the mass of bone, tendons, skin collagen, ligaments, cornea, and interstitial connective tissue. In most organs, especially in the tendons and fascia, collagen type I provides stiffness to bones. It is necessary to withstand body weight, stretch strength, and torsional stiffness [12].

Mature collagen type I found in dense bundles in connective tissue such as tendons or ligaments is responsible for tissue strength [13]. Delayed or abnormal collagen synthesis or tissue protease activity has been identified as a defect that facilitates hernia formation [14]. Damaged collagen regulation in inguinal hernias can be explained by genetic changes, environmental factors, and collagen deposition [15]. Gene polymorphisms usually occur in the region of gene regulation, which is the binding site for the transcription factor Sp1. The base exchange of guanine $(G)$ to thymidine $(T)$ in the intronic Sp1 binding site results in increased expression of the type I alpha 1 (COL1A1) collagen gene [16]. In this study, the expression of the COL1A1 gene in herniated subjects was no different from non-hernia. Although there was no statistically significant difference, there was a decreasing COL1A1 gene expression in hernia patients.

Collagen type III, consisting of thinner fibers, represents the immature collagen found in initial wound healing and inflexible tissue. Type III collagen is collagen that is first formed in wound healing which is subsequently replaced by type I collagen. Type III collagen is an immature isoform present at a greater concentration in the extracellular matrix of patients with incisional and inguinal hernias [12], [17].

In this study, the COL3A1 gene expression in hernia subjects was significantly greater than that of non-hernia subjects. The decrease in collagen type $\mathrm{I} / \mathrm{III}$ in incisional hernias is due to the increase in collagen type III in hernia patients. Connective tissue becoming more elastic and can be the basis for the pathophysiology of the hernia.

The constitutive and systemic increase in collagen type III synthesis can lead to reduced collagen fibril formation in the abdominal wall, which leads to the development of a herniation. Although it is unclear what genetic factor is responsible for the increased synthesis of type III collagen in patients with hernias, individuals with abnormalities in collagen production are associated explicitly with herniation. There was a significant increase in immature type III collagen than the stronger type I collagen in herniated patients. Thus, thinner collagen fibers are produced with reduced biomechanical strength [6], [18].

MMPs function to regulate collagen synthesis and degradation. One type of MMP in humans is MMP2. MMP-2 is the essential proteolytic enzyme in the physiopathology of direct inguinal hernia. Evidence shows a significant increase in patients with direct inguinal hernia transverse fascia compared with patients with indirect hernia. MMP-2 is associated with inguinal hernia formation because it can degrade collagen types I and III [18]. The impaired collagen type I/type III ratio in the fascia of hernia patients has been associated with altered collagen degradation caused by overexpression of MMP [14].

In this study, the expression of the MMP2 gene in herniated subjects was more significant than in non-hernia subjects. Although the difference in MMP2 gene expression in the two groups was not statistically significant, there was a trend of increasing MMP2 in herniated patients.

Based on the reference gen and Livak method, the ratio of collagen type I/III expression in hernia patients with non-hernia is $2: 1$, which means there is a decrease in the ratio compared to the collagen ratio in normal skin. This result is in line with the systematic review conducted by Henriksen et al., which concluded that hernia formation and recurrence were associated with manifestations of collagen metabolism that change with a decrease in the ratio of collagen type I: III [18]. Several other studies examining the ratio of type $1 / I I I$ collagen gene expression in adults and the elderly also showed a decrease in the ratio of type I/III collagen gene expression in hernia cases compared to controls [7], [16]. This study indicates that the increase in COL3A1 synthesis in this study may affect reducing the formation of collagen fibrils on the abdominal wall, which promotes the development of herniation. It can be concluded that an insignificant decrease in COL1A1 gene expression and a significant increase in COL3A1 gene expression can lead to a decrease in the COL1A1/ COL3A1 gene ratio.

This study still has limitations in the number of samples that are not large enough and there is a difference in the age of the groups so that statistically significant differences between the expression of the MMP2, COL1A1, and COL3A1 genes cannot be demonstrated. However, differences in gene expression between the hernia and non-hernia groups were quite visible.

\section{Conclusions}

We found that there was no difference in expression of COL1A1 and MMP2 between the hernia and non-hernia groups. The COL3A1 expression value in hernia patients was significantly higher than in nonhernia patients.

\section{References}

1. AhmedAlenazi A, Alsharif MM, Hussain MA, Alenezi NG, Alenazi $A A$, et al. Prevalence, risk factors and character of 
abdominal hernia in Arar city, Northern Saudi Arabia in 2017 Electron Physician. 2017;9(7):4806-4811. https://dx.doi. org/10.19082/4806

2. Oberg S, Andresen K, Rosenberg J. Etiology of inguinal hernias: a comprehensive review. Front Surg. 2017; 4:52. https://dx.doi. org/10.3389/fsurg.2017.00052

3. Bongu A, Kunac A, Blaskewicz CM. Beyond watchful waiting: the burden of inguinal hernia in low income countries. J Am Col Surgery. 2013; 217(3): 133-8. https://doi.org/10.1016/j. jamcollsurg.2013.07.133

4. Burcharth J, Pedersen M, Bisgaard, Pedersen C, Rosenberg J. Nationwide prevalence of groin hernia repair. PLoS One. 2013; 8(1) :e54367. https://doi.org/10.1371/journal.pone.0054367

5. Bucharth J, Pommergaard HC, Bisgaard T, Rosenberg J. Patient-related risk for recurrence after inguinal hernia repair: a systematic review and meta-analysis of observational studies. Surg Innov. 2015; 22(3): 303-17. https://doi. org/10.1177/1553350614552731

6. Klinge U, Binnebosel M, Rosch R, Mertens P. Hernia recurrence as problem of biology and collagen. J Minim Access Surg. 2006; 2(3):151-4. https://dx.doi.org/10.410/0972-9941.27729

7. Rosch $R$, Klinge $U$, Si Z, Junge $K$, Klosterhalfen $B$, Schumpelick V. A role for the collagen I/III and MMP-1/-13 genes in primary inguinal hernia? BMC Med Genet. 2002; 3:2. https://doi.org/10.1186/1471-2350-3-2

8. Henriksen NA. Systemic and local collagen turnover in hernia patients. Dan Med J. 2016; 63(7): B5265.

9. Quintas ML, Rodrigues CJ, Yoo JH, Rodrigues Junior AJ. Age related changes in the elastic fiber system of the interfoveolar ligament. Rev Hosp Clin Fac Med Sao Paulo. 2000;55(3):83-6. https://doi.org/10.1590/s0041-87812000000300003
10. Claus CMP, Rocha GM, Campos ACL, Paulin JAN, Coelho JCU. Mesh displacement after bilateral inguinal hernia repair with no fixation. JSLS. 2017;21(3):33. https://doi.org/10.4293/ jsls.2017.00033

11. Lau H, Fang C, Yuen WK, Patil NG. Risk factors for inguina hernia in adult males: A case-control study. Surgery. 2007;141(2):262-6.

12. Rosch R, Junge $K$, Lynen $P$, Mertens $P R$, Klinge $U$, Schumpelick V. Hernia- a collagen disease? Eur Surg. 2003; 35(1):11-15

13. Antoniou SA, Antoniou GA, Granderath FA, Simopoulos C. The role of matrix metalloproteins in the pathogenesis of abdominal wall hernias. Eur J Clin Invest. 39(11): 953 - 959. https://doi. org/10.1111/j.1365-2362.2009.02199.x

14. Franz MG. The biology of hernia formation. Surg Clin North Am. 2008; 88(1): 462-471. https://dx.doi.org/10.1016/j. suc.2007.10.007

15. Jansen $\mathrm{PL}$, Rosch R, Rezvani M, Mertens PR, Junge $\mathrm{K}$, et al. Hernia fibroblast lack $\beta$-estradiol induced alterations of collagen gene expression. BMC Cell Biol. 2006;7: 36. https://doi. org/10.1186/1471-2121-7-36

16. Sezer S, Şimşek N, Çelik HT, Erden G, Ozturk G, et al. Association of collagen type I alpha 1 gene polymorphism with inguinal hernia. Hernia. 2014;18(4):507-12. https://doi. org/10.1007/s10029-013-1147-y

17. Donahue TR, Hiatt JR, Busuttil RW. Collagenase and surgical disease. Hernia (2006), 10:478-485. https://doi.org/10.1007/ s10029-006-0146-7

18. Henriksen NA, Yadete DH, Sorensen LT, Ågren MS, Jorgensen LN. Connective tissue alteration in abdominal wall hernia. Br J Surg. 2011;98(2):210-9. https://doi.org/10.1002/ bjs.7339 